\title{
PUBLIC AND PRIVATE ROLES IN MALARIA CONTROL: THE CONTRIBUTIONS OF ECONOMIC ANALYSIS
}

\author{
KARA HANSON \\ Health Policy Unit, London School of Hygiene and Tropical Medicine, London, United Kingdom
}

\begin{abstract}
There has been high profile advocacy and debate about how to increase availability and uptake of effective malaria control interventions. Application of the tools of public economics indicates that market failures occur for a number of effective malaria control interventions due to monopoly, externalities, and information failures, implying a role for public action. However, additional analysis is required to determine the optimal form of public intervention, and how to set priorities. Additional criteria of cost-effectiveness, impact on poverty and catastrophic expenditures, affordability, characteristics of supply and demand, and potential for leakage are invoked to help inform decision making in the field of malaria control policies. Particular emphasis is placed on the connections between public and private actions.
\end{abstract}

\section{INTRODUCTION}

Amid calls for increased funding for infectious disease from the Commission for Macroeconomics and Health ${ }^{1}$ and the creation of the Global Fund for AIDS, TB and Malaria, there has been high profile advocacy and debate about how to increase availability and uptake of effective malaria control interventions. $^{2-4}$ Much of this debate centers around the appropriate roles for the public and private sectors in financing and delivery of malaria control interventions. This article aims to outline how the tools of economic analysis can contribute to these discussions and inform the process of priority setting, together with some of the key information gaps.

\section{PUBLIC ECONOMICS AND THE ROLE FOR GOVERNMENT INTERVENTION IN MALARIA CONTROL}

Conventional economic analysis starts with the tools of public economics that establish the efficiency of private competitive markets in allocating resources. For markets to operate efficiently, a number of criteria must be met: consumers and producers are assumed to have perfect information, there are many firms in the market producing homogeneous goods, and firms are free to enter and exit the market. In this framework, the role for public action (i.e., by national and donor governments) is to undertake financing of interventions only where markets fail to reach a social optimum.

The same economic framework sets out a number of areas where market failure is expected a priori. These are monopoly, public goods and externalities, and information failure (Table 1). All of these are pervasive in the area of malaria control, providing support for extensive public intervention.

First, monopoly in supply, where there is only one producer of a good, can lead to the charging of excessive prices. Patent protection is a mechanism for explicitly protecting monopoly status of pharmaceutical firms over particular products to allow firms to recoup the costs of research and development. While there is widespread agreement that incentives for drug discovery are essential to provide appropriate incentives for pharmaceutical firms to invest in research and development, one consequence is that drugs for diseases that affect poor countries may be unaffordable. This problem has been welldocumented in the case of anti-retroviral drugs for the management of human immunodeficiency virus/acquired immunodeficiency syndrome, due to high-profile advocacy by international non-governmental organizations. A number of mechanisms for public action to promote access to drugs while retaining incentives for pharmaceutical firms have been proposed. These include differential pricing, guaranteed public purchase agreements, licensing of local production, and public-private partnerships to subsidize costs of research and development (Gardiner E, unpublished data).

Second, many malaria control interventions have public goods characteristics or externalities. Public goods are nonrival in consumption (one person's consumption does not reduce the quantity available for another to consume) and nonexcludable (it is impossible to exclude those who do not pay for the good from consuming it). As a consequence of these two characteristics, a private seller cannot recoup the value to the consumer and such goods will not be provided in private markets. Externalities, which can be positive or negative, represent benefits (or costs) of consumption or production that are not fully valued by the consumer/producer. Markets will tend to under provide (for positive externalities) or over provide (for negative externalities) goods with these characteristics.

In malaria control, indoor residual spraying (IRS) can be understood as a public good. The private benefits from IRS are limited in part because the intervention works against mosquitoes that are resting on indoor surfaces after having taken a blood meal. Thus, the benefits to the inhabitants of a sprayed residence are likely to be minimal. The main benefit of IRS is felt at the community level in terms of reduced vectorial capacity of the mosquito population, through reduced longevity. Providing that coverage of physical structures is high enough, IRS provides benefits that are nonexcludable (those who have not sprayed their homes will also benefit), and non-rival (the benefit of reduced vectorial capacity is not reduced by one household's enjoyment of it). Together, these characteristics mean that there will be a "free-rider" problem, and in the limit, there will be no private production at all. Under such circumstances, private markets will not produce enough of the intervention relative to its social benefits.* This justifies public action in the form of financing of a residual spraying program. The same argument

\footnotetext{
* Even in this case private benefits from spraying may arise in the form of protection against other nuisance creatures such as bedbugs. However, these are assumed to be small in relation to the public health benefits.
} 
TABLE 1

Market failures in malaria control*

\begin{tabular}{ll}
\hline Type of market failure & \multicolumn{1}{c}{ Malaria control examples } \\
\hline Monopoly power & Patient protection of new drugs \\
Public goods/externalities & Mass effect of ITNs and environmental control measures \\
& Reduced drug resistance from use of ACT \\
& Reduced transmission from use of ACT \\
Information failures & Lack of knowledge about effective means of treatment and prevention \\
& Lack of knowledge about how to take complex ACT regimens \\
Poverty & Limited ability to pay for costly interventions such as ACT, ITNs \\
\hline *ITNs $=$ insecticide-treated nets; ACT $=$ artemisinin-based combination therapy.
\end{tabular}

applies to environmental measures to reduce mosquito breeding places.

Most other malaria control interventions are mixed private and public goods, that is, they provide significant private benefit, and therefore there will be some degree of willingnessto-pay for them. However, because there are positive externalities to their consumption, private demand will fall short of the socially optimal level. For example, untreated mosquito nets are primarily a private good that provide a measure of personal protection ${ }^{5}$ as long as they are without holes. Insecticide treatment of nets boosts this individual effect by protecting users even when there are holes in the net, but in addition confers a mass effect through reduction of mosquito longevity, which benefits even those not sleeping under a net. ${ }^{6-9}$ For this reason, there is a strong economic rationale for public intervention to ensure adequate uptake of insecticide for net re-treatment, and for long-lasting nets, when they become more widely available, to increase their use.

Artemisinin-based combination therapy (ACT) is another example of a mixed good that offers the possibility of improved therapeutic effectiveness at the individual level, plus the potential positive externalities of reduced malaria transmission and reduced growth of drug resistance. The potential for reduction in transmission, which arises because artemisinin acts on the gametocyte phase of the parasite cycle, has been demonstrated in studies in refugee camps on Thailand's border with Myanmar. ${ }^{10,11}$ Other studies suggested that ACT in these areas has allowed efficacy of mefloquine (the product used in combination with artemisinin) to stabilize or even recover. ${ }^{12}$

An additional challenge, however, is that the existence and size of some positive externalities may vary across contexts. For instance, there is some doubt as to whether the two positive externalities associated with ACT are likely to arise in areas of high transmission, such as most of sub-Saharan Africa. ${ }^{13}$ Potential problems are related to differences in malaria epidemiology, health systems and policy, and human behavior. Concerning the first, the much higher entomologic inoculation rates in many parts of sub-Saharan Africa raise the risk of re-exposure after treatment, when blood drug levels are sub-therapeutic. This could be a source of selective pressure. Furthermore, due to acquired immunity in high transmission areas, a smaller proportion of infected individuals are symptomatic and therefore seek treatment: these asymptomatic individuals may be a source of gametocytes, maintaining high levels of transmission.

An important health system-related factor is the predominance of clinical diagnosis, which results in high levels of over-diagnosis of malaria and consequent overtreatment, ${ }^{14,15}$ which may increase overall selective drug pressure if treated individuals are subsequently infected, and poor drug use by many providers in the public and private sectors. ${ }^{16,17} \mathrm{~A}$ second health system-related factor is the increasing emphasis in sub-Saharan Africa on home-based treatment by increasing the accessibility of malaria drugs and caregivers' knowledge about how to use them. This is in response to the rapidity with which malaria infection can progress quickly to severe or fatal illness, with many children dying in the home without recourse to formal health care providers. The strategy also aims to capitalize on the fact that the majority of treatment already takes place in the home, with drugs purchased from shops or acquired in previous visits to health facilities. ${ }^{18-22}$ Concerns have been raised, however, that such strategies may lead to increased misuse of drugs and consequent selective pressure in the context of ACT, with its more complex therapeutic regimen. ${ }^{23}$ In contrast, in areas of low transmission, the trend has been towards increased control of drugs within the health facility, with greater use of diagnostic technologies.

Human behavior, which is likely to both influence and be influenced by epidemiological factors, could also undermine the potential for externalities arising from ACT. There is a substantial degree of self-treatment of malaria in Africa, and associated inappropriate drug use. In the context of ACT, this could lead to inappropriate dosing and inadequate adherence to more complex ACT treatment regimens, and potentially to the use of either of the drugs as monotherapy. Thus, given the complexity of the relationship between transmission and drug resistance, it is not clear that the societal benefits of ACT that have been demonstrated in southeast Asia will be seen in the sub-Saharan African context. ${ }^{13}$

A third source of market failure is information failure. Such problems may take the form of information asymmetry between a consumer and their provider "agent" (for example, a doctor or pharmacist who is asked to guide them as to the most appropriate course of action), who may behave opportunistically and take advantage of the consumer's ignorance about the most appropriate treatment. There may also be a more basic information failure in the form of provider and patient ignorance about the most appropriate treatment or the availability of effective means of prevention. For example, a number of studies have identified low levels of provider knowledge of correct antimalarial drug dosages. ${ }^{16,17,24}$ Consumer knowledge of correct dosages is also poor, often leading to both under- and over-dosing. The benefits of insecticide-treated nets (ITNs) are still not widely known in some communities. For instance, in one district of Tanzania in 1999 only $45 \%$ of household heads had heard of ITNs (Kikumbih $\mathrm{N}$, unpublished data). The invisible nature of insecticide treat- 
ment of nets is likely to lead to sub-optimal levels of demand, as shown by low re-treatment rates even in projects where net uptake is high and net treatment vigorously promoted. ${ }^{5,25}$

In contrast to these situations where market failure is expected a priori due to the economic characteristics of the interventions, markets can also fail to deliver socially optimal outcomes in instances of poverty. It is well known that subSaharan Africa bears the greatest share of the burden of malaria, with $90 \%$ of the deaths. While there is little evidence that within poor countries malaria incidence is higher among the poor (Filmer D, unpublished data), poor households are at greatest risk of the most severe consequences of illness, in terms of the risk of death and the economic consequences of costly treatment (Worrall $\mathrm{E}$ and others, unpublished data).

This classification of malaria control interventions according to the standard public economics framework suggests that there is significant scope for public financing to correct market failures, which arise either due to the economic characteristics of the interventions, or to the link between poverty and malaria and its consequences. However, the theory of public economics is silent about how to intervene to achieve better outcomes. For example, should governments subsidize the cost of ITNs, or spend money on public information campaigns that will shift demand towards the socially optimal level? Nor does it aid in prioritizing among market failures. In practice, governments and donors still have to choose among interventions since their budgets do not usually allow them to provide universal coverage of all interventions with public or mixed good characteristics. There are further issues in considering the optimal provision (in contrast to financing) of malaria control interventions. While economists often assume that the incentives associated with for-profit motivation will lead the private sector to deliver interventions more efficiently, the problems with monopoly and information asymmetry outlined earlier mean that private production will not necessarily be optimal. In a "second best" world, no simple economic theorem can guide the choice between public and private provision.

Thus, the standard tools of public economics can help to make the case for public intervention, but are less useful in determining the form that intervention should take, and in setting priorities for public action in financing and providing interventions. However, there are a range of other economic tools that can be applied to inform these policy decisions.

\section{EXPANDING THE ECONOMIC FRAMEWORK: CRITERIA FOR GUIDING PUBLIC ACTION}

In this section, the case for public action to increase uptake of malaria control interventions is taken as given. A number of additional economic tools and perspectives are described that can help to inform policy decisions about the form such intervention should take and how priorities should be set. Key information gaps are also identified.

Cost-effectiveness of interventions. Evidence about the cost-effectiveness of interventions is often used to inform decisions about how to allocate public sector health funds. Costeffectiveness analysis (CEA) provides a framework for systematically comparing the costs and consequences of health interventions, summarizing this in terms of a cost-effectivness ratio (CER). When choosing how to spend a fixed health budget, the procedure is to first rank all possible interventions in terms of their cost-effectiveness, begin implementing the most cost-effective intervention until the disease burden with that disease is eliminated, then continue down the list adopting gradually less cost-effective interventions until the budget is exhausted. This process assumes that the CER is invariant to the scale of intervention: if ratios vary with scale, then efficiency may require switching to the next-best intervention before the first burden is eliminated. ${ }^{26}$ However, because the benefits in CEA are measured in terms of health outcomes (usually disability-adjusted life-years [DALYs] or qualityadjusted life years), it is not possible to compare the benefits of investing in health with other uses of these funds (for example, education or infrastructure development). As a result, CEA cannot be used to argue for increasing the size of the health budget.

In the field of malaria control, analysis by Goodman and others of the cost-effectiveness of malaria interventions showed that many are "attractive" ( $<\$ 100 /$ DALY averted) or "very attractive" ( $<$ \$25/DALY averted) interventions. ${ }^{27}$ For example, insecticide treatment of existing mosquito nets was estimated to cost \$4-10 per DALY averted, providing nets and re-treatment \$19-85 per DALY averted, and intermittent presumptive treatment of pregnant women (IPTp) through existing antenatal services \$4-29 per DALY averted. Such analyses are extremely useful in strengthening the argument for prioritizing malaria control within public sector health budgets.

However, most cost-effectiveness evidence is based on very specific delivery mechanisms. In the case of ITNs, for example, the earlier analysis was costed on the basis of the same delivery mode as used in the main efficacy trials (free nets with regular retreatment by project staff). For IPTp, it was assumed that delivery would be through public sector static health facilities. Little systematic evidence has been collected about costs and health consequences of other delivery approaches, although one study showed that social marketing of ITNs can be at least as cost-effective $(\$ 37-57$ per DALY averted) as public sector delivery. ${ }^{28}$ Costs of alternative delivery mechanisms will also vary across settings. For example, commercial sector delivery of ITNs costs $\$ 3-5$ per net in Tanzania, ${ }^{29}$ but up to $\$ 10$ in Mozambique. ${ }^{30}$

Reaching the poor and protecting against catastrophic expenditures. A further gap in the cost-effectiveness literature is evidence about the cost-effectiveness of reaching different socioeconomic groups. One exception is work associated with the Kilombero and Ulanga Insecticide-Treated Net (KINET) project that showed that social marketing of ITNs is more costly than a pure commercial sector approach, but is more effective at reaching those in the lowest socioeconomic groups and those located outside of village centers (Kikumbih $\mathrm{N}$, unpublished data). A more systematic approach is needed to assessing the costs and consequences of reaching the poorest with essential interventions. ${ }^{31}$

Certain interventions may be so costly that their expense can drive a household into poverty. For poor households, the threshold level at which expenditures become catastrophic is much lower. ${ }^{32}$ Hospital treatment of complicated or severe malaria is one such intervention. A recent review of the literature did not identify any estimates of the cost of inpatient care as a share of household income, ${ }^{33}$ but earlier estimates of the distribution of malaria spending across socioeconomic 
groups in Malawi found little difference across groups in absolute levels of expenditure on hospital admission for malaria, implying that payments are regressive (i.e., are a greater share of total expenditure for the poor than the rich). ${ }^{34}$ In such cases, there is an equity rationale for subsidizing the cost of hospital care. An additional complexity is whether subsidies in this case should be universal or targeted towards specific groups. Evidence from a variety of settings indicates that the rich capture a disproportionate share of the subsidy on hospital treatment in general, providing an argument for closer targeting of public spending. ${ }^{32}$ However, there are a number of practical and political difficulties associated with targeting of subsidies. ${ }^{35}$

Affordability to government. In addition to cost-effectiveness, affordability as it relates to the total cost of an intervention must also be considered. Interventions may be highly cost-effective yet still unaffordable to governments. For instance, it has been estimated that in a typical country, covering the entire population at risk of malaria with ITNs would cost $24 \%$ of the total government health budget. ${ }^{27}$

Characteristics of supply: substitution, quality, and efficiency in public and private delivery. Another important consideration is the availability of substitute providers of an intervention. Where the private sector is already involved in delivering a cost-effective intervention, increased public provision might simply substitute for private provision, leading to no net increase in use or coverage. ${ }^{36}$ In the case of ITNs, it is likely that where there is already a private market for ITNs, public supply would substitute for private supply. This would be inefficient in the sense that individuals who would otherwise have purchased a net at commercial prices will simply shift their consumption to the free public sector. $\dagger$ An accurate picture of the existence of substitute providers (actual or potential) is therefore essential, and requires better information about the entire market for these interventions. The question of potential providers is important, particularly when examining markets for new products such as ITNs: if public involvement means discouraging entry by a commercial sector that would otherwise have entered the market, then this would still be considered to be crowding out (known in economics as the counterfactual argument). A degree of crowding out of the private commercial sector by a subsidized social marketing product was observed in the KINET project (Kikumbih N, unpublished data), and of a less-subsidized social marketing product by a more-subsidized one in another social marketing project in Tanzania (Hanson K, Jones C, unpublished data).

An alternative scenario is one in which public provision can help to build a market for a product, known as "pump priming" in the World Health Organization Strategic Framework $^{29}$ or "crowding in" the private sector. At the aggregate level, donor-funded social marketing in Tanzania over the period 1998 to 2002 can be argued to have encouraged the expansion of the commercial manufacturing and distribution system. The market is now mature enough that the public sector has been able to move out of the business of supplying nets, and focuses on subsidizing insecticide, continued de-

\footnotetext{
$\dagger$ In the case of pure public goods, such as IRS, crowding out is not an
} issue because no private market will exist. mand creation, and supporting the commercial sector in strengthening their distribution network.

By competing with the commercial sector, the donorfunded social marketing activities also encouraged it to be more responsive to consumer preferences. The Tanzanian net manufacturers now produce a dazzling variety of shapes, sizes, and colors of nets. In other settings, it has been argued that by providing a high-quality alternative, the public sector has encouraged the private sector to maintain and improve the quality of curative health services. ${ }^{36}$

The degree to which private and public delivery are adequate substitutes depends on their quality and their efficiency. Displacing poor-quality or very expensive private provision with more appropriate and efficient public supply could save resources, particularly if a societal perspective is taken. For instance, as governments begin to change to antimalarial combination therapy, public provision may act as an encouragement to private providers to follow suit. At the same time, it is important to recognize the very poor quality of services provided in many public facilities: governments fail as well as markets, and the existence of a vibrant private informal drug market may be a good indication of problems of quality and patient satisfaction in the public sector.

Characteristics of the demand for services. Another critical issue is the responsiveness of demand for malaria interventions to price (the price elasticity of demand). For example, if demand is highly sensitive to price, then selling subsidized ITNs through public health facilities could have a dramatic impact on coverage. In contrast, the subsidy could have little effect if demand is price inelastic. To date, information about price elasticity of demand for ITNs is confined to hypothetical willingness-to-pay questions, and there is no empirical evidence of willingness to pay for ACT. ${ }^{37}$ There is a critical need for better information on the price elasticity of demand for ITNs and ACT based on actual market behavior to guide decisions about how much to subsidize prices to increase coverage.

If the aim of government intervention is to encourage increased coverage among the poor, the income elasticity of demand must also be known. If an intervention is highly income elastic, then most of the benefits of any subsidized provision are likely to be captured by the better-off. A related issue is the types of providers that poor people are most likely to use: for example, within the broad category of private providers, poor people may be more likely to use informal drug sellers than formal health service providers. ${ }^{38}$ Policy efforts to encourage coverage of effective interventions among the poor need to take account of these use patterns.

Potential for leakage and cross-border movements. Where there are significant price differentials across shared international borders, and problems of control and monitoring of public sector supplies, illegal cross-border flows of commodities are likely to come about. The potential for such crossborder flows clearly exists with such higher value commodities as ACT and ITNs, where the incentives to divert public supplies may be considerable. Careful monitoring is needed, and there may be arguments for a regional approach to policy.

\section{DISCUSSION AND CONCLUSIONS}

There are powerful economic arguments to support public action to increase the uptake of effective malaria control in- 
terventions. Market failures are likely to arise from monopoly power of pharmaceutical firms, positive externalities associated with insecticide-treatment of nets, residual spraying, environmental control, and, potentially, ACT and information problems. In addition, commercial markets are unlikely to guarantee adequate uptake of interventions in contexts of widespread poverty.

The challenge is to prioritize areas for public action. Existing funding for malaria control is inadequate to fund the full menu of effective interventions with market failures, and even if considerable additional funds are made available through global initiatives such as the Global Fund for AIDS, Malaria and TB, priorities will still need to be set. In face of information failures and externalities, public funding should be focused on those interventions that are most cost-effective. Existing evidence shows that most existing malaria control interventions are very cost-effective, costing less than $\$ 100 /$ DALY averted. There are important information gaps, however, relating to the costs and consequences of alternative delivery strategies, and the costs of reaching the poor.

Other criteria, too, must be applied to the choice of what the public sector should do. To the extent that public policy is concerned with the impact of malaria on poverty, costly interventions that can have catastrophic consequences for households should be considered.

Perhaps most challenging is to consider the link between public and private sector activity. On the one hand, private delivery of interventions such as ITNs and drugs offers the potential to extend coverage and focus public sector resources on those most in need; at the same time, the many deficiencies of the private sector in terms of quality and reach of distribution networks must be recognized. These factors will differ across contexts, requiring careful assessment of local conditions and provider characteristics. What is clear, however, is that public action will influence the private sector, and the likely impact needs to be assessed in making public choices.

Future technological developments may simplify or make more complex the relationship between optimal public and private roles. For instance, it is currently relatively inexpensive and feasible to publicly subsidize insecticide for net treatment, but the binding of public and private benefits that will come about through long-lasting nets will require new funding mechanisms, such as licensing agreements for manufacturers.

Finally, it is important to recognize that financing and provision can often be separated in delivering interventions. Even if there is a strong case for public subsidy due to market failures, it is not necessarily the case that this must be delivered through public sector channels. Other options exist, such as vouchers which can be redeemed at private providers, ${ }^{39}$ or contracting of private providers. The choice of how to intervene will require a careful assessment of the options available, and their suitability to specific contexts.

Received August 21, 2003. Accepted for publication February 20, 2004.

Financial support: Kara Hanson is a member of the Health Economics and Financing Program, which is funded by a program grant from the United Kingdom Department for International Development (DFID).

Disclaimer: The facts presented and views expressed are those of the author and do not necessarily reflect the policies of DFID.
Author address: Kara Hanson, Health Policy Unit, London School of Hygiene and Tropical Medicine, Keppel Street, London WC1E 7HT, United Kingdom, Telephone: 44-20-7927-2267, Fax: 44-20-7637-5391, E-mail: kara.hanson@lshtm.ac.uk.

\section{REFERENCES}

1. WHO Commission on Macroeconomics and Health, 2001. Macroeconomics and Health: Investing in Health for Economic Development. Report of the Commission on Macroeconomics and Health. Geneva: World Health Organization.

2. Médecins Sans Frontières, 2003. ACT Now to Get Malaria Treatment that Works to Africa. Geneva: Médecins Sans Frontières. Access to Essential Medicines Campaign, www.accessmedmsf.org. Accessed December 23, 2003.

3. Curtis CF, Maxwell CA, Lemnge M, Kilama WL, Steketee RW, Hawley WA, Bergevin Y, Campbell CC, Sachs J, Teklehaimanot A, Ochola SA, Guyatt HL, Snow RW, 2003. Scaling-up coverage with insecticide-treated nets against malaria in Africa: who should pay? Lancet Infect Dis 3: 304-307.

4. Lines J, Lengeler C, Cham K, de Savigny D, Chimumbwa J, Langi P, Carroll D, Mills AJ, Hanson K, Webster J, Lynch M, Addington W, Hill J, Rowland M, Worrall E, MacDonald M, Kilian A, 2003. Scaling-up and sustaining insecticide-treated net coverage. Lancet Infect Dis 3: 465-466.

5. Armstrong Schellenberg JR, Abdulla S, Nathan R, Mukasa O, Marchant TJ, Kikumbih N, Mushi AK, Mponda H, Minja H, Mshinda H, Tanner M, Lengeler C, 2001. Effect of large-scale social marketing of insecticide-treated nets on child survival in rural Tanzania. Lancet 357: 1241-1247.

6. Binka F, 1998. Impact of spatial distribution of permethrinimpregnated bed nets on child mortality in rural northern Ghana. Am J Trop Med Hyg 59: 80-85.

7. Maxwell CA, Myamba J, Njunwa KJ, Greenwood BM, Curtis CF, 1999. Comparison of bednets impregnated with different pyrethroids for their impact on mosquitoes and on re-infection with malaria after clearance of pre-existing infections with chlorproguanil-dapsone. Trans $R$ Soc Trop Med Hyg 93: 4-11.

8. Howard SC, Omumbo J, Nevill C, Some ES, Donnelly CA, Snow RW, 2000. Evidence for a mass community effect of insecticide-treated bednets on the incidence of malaria on the Kenyan coast. Trans $R$ Soc Trop Med Hyg 94: 357-360.

9. Hawley WA, Phillips-Howard PA, Ter Kuile FO, Terlouw DJ, Vulule JM, Ombok M, Nahlen BL, Gimnig JE, Kariuki SK, Kolczak MS, Hightower A, 2003. Community-wide effects of permethrin treated bednets on child mortality and morbidity in Western Kenya. Am J Trop Med Hyg 68 (suppl): 121-127.

10. Price RN, Nosten F, Luxemburger C, Ter Kuile FO, Paiphun L, Chongsuphajaisiddhi T, White NJ, 1996. Effects of artemisinin derivatives on malaria transmissibility. Lancet 347: 1654-1658.

11. Price RN, Nosten F, Luxemburger C, van Vugt M, Phaipun L, Chongsuphajaisiddhi T, White NJ, 1997. Artesunate/ mefloquine treatment of multi-drug resistant falciparum malaria. Trans R Soc Trop Med Hyg 91: 574-577.

12. Nosten F, van Vugt M, Price R, Luxemburger C, Thway KL, Brockman A, McGready R, ter Kuile F, Looareesuwan S, White NJ, 2000. Effects of artesunate-mefloquine combination on incidence of Plasmodium falciparum malaria and mefloquine resistance in western Thailand: a prospective study. Lancet 356: 297-302.

13. Bloland PB, Ettling M, Meek S, 2000. Combination therapy for African malaria: hype or hope? Bull World Health Organ 78: 1378-1388.

14. Olivar M, Develoux M, Chegou Abari A, Loutan L, 1991. Presumptive diagnosis of malaria results in a significant risk of mistreatment of children in urban Sahel. Trans $R$ Soc Trop Med Hyg 85: 729-730.

15. Sowunmi A, Akindele JA, 1993. Presumptive diagnosis of malaria in infants in an endemic area. Trans $R$ Soc Trop Med Hyg 87: 422.

16. Clarke E, Tagoe EB, Nortey E, Marfo C, 1992. Are they Doing it Right? A Survey on Drug Use in the Management of Malaria in the Accra Metropolitan Area Health Institutions. Accra, Ghana: Ministry of Health. 
17. Marsh VM, Mutemi WM, Muturi J, Haaland A, Watkins WM, Otieno G, Marsh K, 1999. Changing home treatment of childhood fevers by training shop keepers in rural Kenya. Trop Med Int Health 4: 383-389.

18. McCombie SC, 1996. Treatment seeking for malaria-a review of recent research. Soc Sci Med 43: 933-945.

19. Deming MS, Gayibor A, Murphy K, Jones TS, Karsa T, 1989. Home treatment of febrile children with antimalarial drugs in Togo. Bull World Health Organ 67: 695-700.

20. Ejezie GC, Ezedinachi EN, Usanga EA, Gemade EI, Ikpatt NW, Alaribe AA, 1990. Malaria and its treatment in rural villages of Aboh Mbaise, Imo State, Nigeria. Acta Trop 48: 17-24.

21. Snow RW, Peshu N, Forster D, Mwenesi H, Marsh K, 1992. The role of shops in the treatment and prevention of childhood malaria on the coast of Kenya. Trans R Soc Trop Med Hyg 86: 237-239.

22. Mnyika KS, Killewo JZJ, Kabalimu TK, 1995. Self-medication with antimalarial drugs in Dar es Salaam, Tanzania. Trop Geogr Med 47: 32-34.

23. Bloland P, Kachur SP, Williams HA, 2003. Trends in antimalarial drug deployment in sub-Saharan Africa. J Exp Biol 206: 37613769.

24. Slutsker L, Chitsulo L, Macheso A, Steketee RW, 1994. Treatment of malaria fever episodes among children in Malawi: results of a KAP survey. Trop Med Parasitol 45: 61-64.

25. Snow RW, McCabe E, Mbogo CNM, Molyneux CS, Some ES, Mung'ala V, Nevill CG, 1999. The effect of delivery mechanisms on the uptake of bed net re-impregnation in Kilifi District, Kenya. Health Policy Plann 14: 18-25.

26. Musgrove P, 1999. Public spending on health care: how are different criteria related? Health Policy 47: 207-223.

27. Goodman C, Coleman P, Mills A, 1999. Cost-effectiveness of malaria control in sub-Saharan Africa. Lancet 354: 378-385.

28. Hanson K, Kikumbih N, Armstrong Schellenberg JAS, Mponda H, Nathan R, Lake S, Mills A, Tanner M, Lengeler C, 2003. Cost-effectiveness of social marketing of insecticide-treated nets for malaria control in the United Republic of Tanzania. Bull World Health Organ 81: 269-276.

29. WHO, 2002. Scaling Up Insecticide-Treated Netting Programs in
Africa: A Strategic Framework for Coordinated National Activity. Geneva: World Health Organization. WHO/CDS/RBM/ 2002.43.

30. Brentlinger PE, Sherr K, Mercer MA, Gloyd S, 2003. Scaling-up and sustaining insecticide-treated net coverage. Lancet Infect Dis 3: 467.

31. Barat LM, Palmer N, Basu S, Worrall E, Hanson K, Mills A, Do malaria control interventions reach the poor? A view through the equity lens. Am J Trop Med Hyg 71 (suppl 2): 174-178.

32. Filmer D, Hammer JS, Pritchett LH, 2002. Weak links in the chain II: A prescription for health policy in poor countries. World Bank Res Observer 17: 47-66.

33. Worrall E, Basu S, Hanson K, 2002. The Relationship between Socio-economic Status and Malaria: A Review of the Literature. Background paper prepared for meeting on "Ensuring that Malaria Interventions Teach the Poor." London: London School of Hygiene and Tropical Medicine.

34. Ettling M, Steketee RW, Macheso A, Schultz LJ, Nyasulu Y, Chitsulo L, 1994. Malaria knowledge, attitudes and practices in Malawi: survey population characteristics. Trop Med Parasitol 45: 57-60.

35. Gilson L, Russell S, Buse K, 1995. The political economy of user fees with targeting: developing equitable health financing policy. J Int Dev 7: 369-401.

36. Hammer JS, Berman P, 1995. Ends and Means in Public-Health Policy in Developing-Countries. Health Policy 32: 29-45.

37. Simon JL, Larson BA, Zusman A, Rosen S, 2002. How will the reduction of tariffs and taxes on insecticide-treated bednets affect household purchases? Bull World Health Organ 80: 892899.

38. Smith E, Brugha R, Zwi A, 2001. Working with Private Sector Providers for Better Health Care, An Introductory Guide. London: Options and the London School of Hygiene and Tropical Medicine.

39. Mushi AK, Armstrong Schellenberg JRM, Mponda H, Lengeler C, 2003. Targeted subsidy for malaria control with treated nets using a discount voucher system in southern Tanzania. Health Policy Plann 18: 163-171. 